\title{
Legionella spp. ¿Ausente en los hospitales de Costa Rica?
}

\section{Artículo Original}

Evelyn Rodríguez, María del M. Gamboa, María L. Arias.

Laboratorio de Investigación en Bacteriología Anaerobia y Centro de Enfermedades Tropicales, Facultad de Microbiología, Universidad de Costa Rica, Costa Rica.

\section{RESUMEN.}

Introducción. Legionella spp. se encuentra ampliamente distribuida en ambientes húmedos naturales, así como en tanques de almacenamiento de agua potable, torres de enfriamiento, aires acondicionados y duchas, entre otros. Varias especies, especialmente L. pneumophila, son capaces de originar una enfermedad respiratoria aguda que puede conducir a neumonías fatales sobre todo en pacientes inmunocomprometidos o con enfermedad pulmonar concomitante. En Costa Rica no se ha informado de casos clínicos ni de hallazgos de laboratorio que confirmen la presencia de Legionella, desconociéndose la realidad al respecto; a fin de contribuir a esclarecerla se decidió investigar su presencia en el ambiente hospitalario.

Materiales y Métodos. Se analizaron 160 muestras de aguas provenientes de 56 aires acondicionados y 104 respiradores de los cuatro hospitales costarricenses más importantes. Las muestras fueron recolectadas en bolsas plásticas estériles, que se mantuvieron en frío hasta su análisis en el laboratorio. Para el aislamiento de Legionella se siguió la metodología recomendada por el Centro de Control y Prevención de Enfermedades (CDC), utilizando L. pneumophila ATCC 33152 como cepa control. Se realizó también cultivo de amebas, a fin de evaluar el posible crecimiento de Legionella en ellas.

Resultados. En ninguna de las 160 muestras analizadas fue posible el aislamiento de Legionella spp., a pesar de que en todos los muestreos se recuperó la cepa control inoculada en muestras negativas. Tampoco se aislaron amebas de vida libre en las ninguna de las muestras.

Conclusiones. Con este estudio se demuestra que Legionella spp. no se encuentra presente o lo está en muy baja cantidad en el ambiente hospitalario costarricense, lo que correlaciona con la ausencia de casos clínicos documentados. Costa Rica sería otro de los países de Latinoamérica en los que su hallazgo no es frecuente.

(Rev Biomed 2002; 13:165-169)

Palabras clave: Legionella, L. neumophilla,

Solicitud de sobretiros: Evelyn Rodríguez, Facultad de Microbiología, Universidad de Costa Rica, Ciudad Universitaria "Rodrigo Facio", Costa Rica, Centro América. E-mail: evelynr@cariari.ucr.ac.cr 
E Rodríguez, M del M Gamboa, ML Arias.

infección intrahospitalaria, neumonía, Costa Rica.

\section{SUMMARY.}

\section{Legionella spp. Absent in Costa Rican} hospitals?

Introduction. Legionella spp. is widely distributed in natural humid habitats, as well as in drinking water tanks, cooling towers, air conditioning systems, and showers. Various species, predominantly $L$. pneumophila, can originate an acute respiratory disease that can lead to fatal pneumonia, especially in immunocompromised patients or those with concomitant pulmonary disease. In Costa Rica, there are no reports of clinical cases, nor laboratory isolations that confirm the presence of this bacterium, so there is a lack of knowledge in this matter. In order to contribute to clarify this situation, we decided to investigate its presence in hospital environments.

Material and methods. 160 water samples coming from 56 air conditioning systems and 104 respirators from the four most important Costa Rican hospitals were analyzed. Samples were collected in sterile plastic bags and kept cold until their analysis at the laboratory. For isolation of Legionella, the methodology recommended by CDC (Centers for Disease Control) was employed, using L. pneumophila ATCC 33152 as control. Amoebae culture was also performed in order to evaluate the possible growth of Legionella within them.

Results. No Legionella strains were isolated from any of the 160 analyzed samples, even though the control strain was recovered from negative samples that had been inoculated; neither amoebae were isolated from any of the samples.

Conclusion. This study demonstrated that Legionella is not present, or it is present at a very low concentration, at the Costa Rican hospital environment, correlating with the absence of reported clinical cases. Costa Rica would be one of the Latin American countries where its presence is not frequent. (Rev Biomed 2002; 13:165-169)
Key words: Legionella, L. neumophila, pneumonia, intrahospital infections, Costa Rica.

\section{INTRODUCCIÓN.}

Legionella spp. se encuentra ampliamente distribuida en ambientes húmedos: ambientes acuáticos naturales, fuentes de agua potable, duchas, aires acondicionados, humedificadores y sistemas de ventilación asistida, entre otros (1). Incluso, se ha sugerido que los baños tipo jacuzzi en Europa y Norte América pueden ser una fuente de infección por Legionella (2). Aunque no siempre pueden identificarse los factores asociados con su aislamiento (3), la convivencia con otros microorganismos es importante para su supervivencia y crecimiento, especialmente con protozoarios, pues se ha demostrado su multiplicación intracelular en amebas $(3,4)$. Esta bacteria es fastidiosa, requiere de cisteína y sales de hierro (5), por lo que su presencia puede quedar oculta en el laboratorio debido al sobrecrecimiento de la flora concomitante $(1,3,5)$.

Legionella spp. y muy especialmente $L$. pneumophila, es capaz de originar desde una infección subclínica hasta una enfermedad respiratoria aguda, febril, de severidad variada, que puede conducir a neumonías fatales $(1,3)$. Se sabe que la enfermedad ocurre tanto en forma endémica como epidémica, estimándose en 25000 el número de casos por año que ocurren en el mundo.

Las neumonías nosocomiales producidas por Legionella, así como las adquiridas fuera del hospital representan del $1 \%$ al $5 \%$ de todas las neumonías (1,3). Aunque Legionella puede causar enfermedad severa en individuos aparentemente sanos, la inmunosupresión, el consumo de alcohol y cigarrillos y la enfermedad pulmonar concomitante son importantes factores de riesgo para el establecimiento de la enfermedad (6).

En Costa Rica no se ha informado de casos clínicos ni de ningún hallazgo de laboratorio por Legionella.

\section{Revista Biomédica}




\section{Legionella spp. ¿Ausente en los hospitales de Costa Rica.}

La falta de un diagnóstico preciso en algunos casos así como la carencia de herramientas diagnósticas adecuadas podrían ser razones para que se asuma que las infecciones por Legionella no están ocurriendo en nuestro medio.

Siendo los sistemas de distribución de aguas reservorios para la diseminación de Legionella (7), se decidió investigar la presencia de Legionella en los cuatro hospitales principales nacionales a partir de aguas acumuladas en sistemas de aires acondicionados y en sistemas de ventilación asistida, en aquellos sitios en las que su presencia pudiera representar un riesgo para los pacientes.

\section{MATERIALES Y MÉTODOS.}

Se analizaron 160 muestras de aguas provenientes de 56 aires acondicionados y 104 respiradores de los hospitales: San Juan de Dios, Calderón Guardia, México y Nacional de Niños. Las muestras fueron recolectadas en bolsas plásticas estériles que se mantuvieron en frío, transportadas y analizadas en menos de dos horas en el laboratorio. Se siguió la metodología recomendada por el Centro de Control y Prevención de Enfermedades (8) para el aislamiento de Legionella. Cada muestra de agua se filtró utilizando filtros de policarbonato de 0,22 $\mu \mathrm{M}$, reservando $10 \mathrm{~mL}$ de la muestra original, en los que se resuspendió y agitó el filtro. A partir de esta suspensión se inoculó $0,1 \mathrm{~mL}$ en agar BCYE (Buffered-Charcoal-Yeast-Extract ${ }^{\circledR}$, Oxoid) y 0,1 mL en BCYE más suplemento selectivo con antibióticos (vancomicina, polimixina $\mathrm{B}$ y anisomicina ${ }^{\circledR}$, Oxoid). A fin de eliminar la flora contaminante se realizó un tratamiento ácido de la suspensión, que consistió en mezclar $1 \mathrm{~mL}$ de la muestra suspendida con $1 \mathrm{~mL}$ de amortiguador ácido HCL-KCl e incubar a temperatura ambiente por 15-30 min, después de lo cual se neutralizó con $1 \mathrm{~mL}$ de $\mathrm{KOH} 0,1 \mathrm{~N}$. Posteriormente se inoculó 0,1 mL en BCYE y 0,1 ml en BCYE más antibióticos. Todas las placas se incubaron en atmósfera húmeda y aumentada de $\mathrm{CO}_{2}$, a $35^{\circ} \mathrm{C}$ por 72 horas y hasta por 7 días. Las colonias en BCYE se analizaron por tinción de Gram y se evaluó su crecimiento en Agar Sangre (AS); las que correspondieran a bacilos Gram negativos y que demostraran ausencia de crecimiento en AS y crecimiento en BCYE serían analizadas utilizando antisueros polivalentes y específicos para Legionella.

El remanente de la suspensión de muestra con el filtro se utilizó para inocular un agar no nutritivo ( $0,5 \%$ de $\mathrm{NaCl}, 1,5 \%$ de agar) para el cultivo de amebas de vida libre (9). Estas placas se incubaron a temperatura ambiente y se examinaron por 15 días en el microscopio de alto poder seco.

Cada vez que se realizaron los estudios con las muestras hospitalarias se corrió en paralelo la metodología con la cepa control de Legionella pneumophila ATCC 33152.

\section{RESULTADOS Y DISCUSIÓN.}

Las técnicas aquí descritas para el aislamiento y cultivo de Legionella se validaron utilizando una cepa control de Legionella pneumophila (ATCC 33152). Se inocularon muestras de agua estéril con concentraciones conocidas de Legionella pneumophila y siempre fue posible recuperarla. Sin embargo, encontramos que el tratamiento ácido disminuye en un $90 \%$ la cantidad de bacterias, valor más alto que el informado por Boulanger y Edelstein (10) quienes logran recuperar aproximadamente el $50 \%$ de inoculo inicial. Además, siempre se pudo recuperar la cepa control en todos los experimentos paralelos a las muestras.

A pesar de lo anterior, en ninguna de las 160 muestras analizadas fue posible el aislamiento de Legionella spp.; esto podría deberse a su total ausencia o a su presencia en muy bajo número. Al respecto, se ha demostrado que la detección de muy bajas concentraciones de L. pneumophila es excepcionalmente difícil, aún en ausencia de bacterias contaminantes o sustancias inhibitorias (10).

Es conocido que Legionella spp. es capaz de

Vol. 13/No. 3/Julio-Septiembre, 2002 


\section{E Rodríguez, M del M Gamboa, ML Arias.}

reproducirse intracelularmente en amebas de vida libre como Hartmanella, Acanthamoeba y Naegleria, de manera similar a como lo hace en monocitos y macrófagos humanos $(3,4)$. En nuestro estudio las muestras de agua también fueron negativas por amebas, siendo esta ausencia una de las posibles razones por las cuales no se aisló Legionella spp.

La multiplicación de L. pneumophila en tuberías ocurre entre $25 \mathrm{y} 42^{\circ} \mathrm{C}(11,12)$, ya que las muestras de agua de respiradores estaban a $37^{\circ} \mathrm{C}$ y las de aires acondicionados a temperatura ambiente, la temperatura no fue un obstáculo para su aislamiento. El uso de tuberías de cobre limita considerablemente el aislamiento de $L$. pneumophila (11). Este factor sin embargo, tampoco puede ser considerado en este estudio, pues ni el agua de los respiradores ni el agua acumulada en los aires acondicionados habría pasado por tuberías de este tipo.

En Costa Rica, es frecuente el uso de cloro residual como agente desinfectante en las líneas de agua potable, práctica que ha demostrado, en otros países, una mayor probabilidad de legionelosis nosocomial (13). A pesar de lo anterior, en nuestro país no se han diagnosticado casos de esta enfermedad, lo que aunado al hecho de que no aislamos la bacteria en los hospitales, hace pensar en la ausencia o baja frecuencia de esta bacteria en el medio.

Aunque las neumonías por Legionella son un problema importante en Norte América y Europa $(4,14)$, en Latinoamérica los hallazgos han sido mucho menos frecuentes y Costa Rica no parece ser la excepción. En Chile Roncoroni y García (15) no aislaron Legionella en ninguna de las muestras de agua o esputo de 18 centros hospitalarios estudiados, a pesar de que ya había sido informado el primer caso de neumonía por Legionella (16). Lobos y colaboradores (17) también en Chile, utilizando técnicas de inmunofluorescencia en un estudio retrospectivo, encontraron dos casos positivos de 50 muestras de lavado broncoalveolar. En Brasil, Mendoza y colaboradores (18) no encontraron (ni serológicamente ni por cultivo de muestras clínicas y de aguas) L. pneumophila al estudiar 55 casos de neumonía; Meira y colaboradores (19) informan un caso y Palombimi y colaboradores (20) encuentran dos casos en 15 pacientes, todos con neumonías. En Argentina, la neumonía por Legionella es un hecho infrecuente (21), mientras que en Cuba se informa hasta 1997 del primer aislamiento de L. bozemani en muestras ambientales hospitalarias sin demostrar la relación con cuadros respiratorios (22) y en México, hasta 1995 se habían reportado sólo dos casos de neumonía por L. pneumophila (23).

Con este estudio logramos demostrar que Legionella spp. no se encuentra presente o lo está en muy baja cantidad en el ambiente hospitalario costarricense, lo que correlaciona con la ausencia de casos clínicos documentados. Es importante señalar que cuando ha existido evidencia clínica apoyada por el diagnóstico de laboratorio se ha logrado el aislamiento de Legionella pneumophila del ambiente hospitalario en altos porcentajes (24), situación que no se está presentando en nuestro medio. Colateralmente, en un estudio ambiental realizado por el Instituto Costarricense de Acueductos y Alcantarillados tampoco se encontró Legionella en más de 100 muestras ambientales (aguas de río, de aires acondicionados y de refrigeradores; Carmen Valiente, comunicación personal). Para confirmar esta aparente ausencia de Legionella, podrían realizarse estudios serológicos y determinaciones utilizando pruebas de reacción en cadena de la polimerasa (PCR), técnicas más sensibles que las técnicas de cultivo (24).

\section{REFERENCIAS.}

1.- Whelan C. Legionella species. En: Mahon CR, Manuselis G, editores. Diagnostic Microbiology. 2a . ed. Filadelfia: WB Saunders Co; 2000. p.447-56.

2.- Nakadate T, Yamauchi K, Inoue H. An outbreak of Legionnaire's disease associated with a Japanese spa. Nihon Kokyuki Gakkai Zasshi 1999; 37:601-7.

\section{Revista Biomédica}




\section{Legionella spp. ¿Ausente en los hospitales de Costa Rica.}

3.- Winn WC Jr. Legionella. En: Murray P, editor en jefe. Clinical Microbiology. $6^{\mathrm{a}}$. ed. Washington DC: ASM Press; 1995. p.533-47.

4.- Breiman RF, Butter JC. Legionnaires' disease: clinical, epidemiological, and public health perspectives. Am J Infect Control 1998; 26:8-11.

5.- Viswanathan VK, Cianciotto NP. Role of iron acquisition in Legionella pneumophila virulence. ASM News 2001; 67:253-8.

6.- Tkatch LS, Kusne S, Irish WD, Krystofiak S, Wing E. Epidemiology of Legionella pneumophila and factors associated with legionella-related mortality at a tertiary care center. Clin Infect Dis 1998; 27:1479-86.

7.- Goetz AM, Stout JE, Jacobs SL, Fisher MA, Ponzer RE, Drenning S, Yu VL. Nosocomial legionnaire¥s disease discovered in community hospitals following cultures of the water system: seek and ye shall find. Am J Infect Control 1998; 26:8-11.

8.- Centers for Disease Control. Procedures for recovery of Legionella from the environment. US, Department of Health and Human Service, Atlanta 1994; p.1-13.

9.- Sanden GN, Morrill WE, Fields BS, Breiman RF, Barbaree JM. Incubation of water samples containing amoebae improves detection of Legionella by the culture method. Appl Environ Microbiol 1992; 58:2001-4.

10.- Boulanger C, Edelstein P. Precision and accuracy of recovery of Legionella pneumophila from seeded tap water by filtration and centrifugation. Appl Environ Microbiol 1995; 61:1805-09.

11.- Rogers J, Dowsett, Dennis PJ, Lee JV, Keevil CW. Influence of temperature and plumbing material selection on biofilm formation and growth of Legionella pneumophila in a model potable water system containing complex microbial flora. Appl Environ Microbiol 1994; 60:1585-92.

12.- Szewzyk U, Szewzyk R, Manz W, Schleifer K. Microbiological safety of drinking water. Annu Rev Microbiol 2000; 54:81-127.

13.- Kool JL, Carpenter JC, Barry SF. Effect of monochloramine disinfection of municipal drinking water on risk of nosocomial legionnaires' disease. Lancet 1999; 353:272-7.
14.- Jarraud S, Reyrolle M, Riffard S, Lo Presti F, Etienne J. Legionnaires' disease in travellers. Bull Soc Pathol Exot 1998; 91:486-9.

15.- Roncoroni AJ, García C. Legionella sp. en infecciones respiratorias agudas y muestras de aguas hospitalarias. Rev Chil Infect 1991; 8:32-4.

16.- González P, Vicencio M, Maldonado A. Neumonía por Legionella: primera comunicación de un caso diagnosticado en Chile. Enferm Respir Cir Torac 1987; 3:266-71.

17.- Lobos MT, Carstens M, Pfenninger A, Moreno R. Diagnóstico de neumonía por Legionella pneumophila mediante la técnica de inmunofluorescencia directa del lavado broncoalveolar. Rev Chil Enferm Respir 1994; 10:71-7.

18.- Mendoça M, Souza BA, Souza ET, Paula A. Estudo etiológico das pneumonias hospitalares: bactérias aeróbicas. Arq Bras Med 1988; 62:413-5.

19.- Meira DA, Fabris VE, Arakaki D, Correia F, Teixeira UA. Pneumonia por Legionella pneumophila com insuficiência respiratória aguda e evoluço fatal: relato de caso em Botucatu-Säo Paulo. Arq Bras Med 1993; 67:257.

20.- Palombini B, Stoltz C, Villanova CA. Tratamento da pneumonia atİpica adquirida na comunidade (PAC): resultados de um estudo aberto. RBM Rev Bras Med 1997; 54: 54-7.

21.- Luna CM. Neumonía por Legionella, un hecho infrecuente en Argentina ¿Diferente epidemiología o marcador de desarrollo? Medicina 1999; 59:311-2.

22.- Regalado L, Alfonso MJ, Verdera J, Selman-Houssein E, Hernández S. Aislamiento de Legionella bozemani. Primer reporte en Cuba. Rev Cuba Hig Epidemiol 1997; 35:111-6.

23.- Huerta J, Lisker A, Núñez RC, Kimura K, Vázquez $\mathrm{S}$, Lázaro JL. La pneumonİa atİpica por Legionella pneumophila: informe del segundo caso en México. Gac Med Mex 1995; 131:587-90.

24.- Köhler JR, Maiwald M, Lück PC, Helbig JH, Hingst V, Sonntag HG. Detecting legionellosis by unselected culture of respiratory tract secretions and developing links to hospital water strains. J Hosp Infect 1999; 41:301-11. 